\title{
Avaliação da atividade antimicrobiana in vitro do gás ozônio
}

Com o surgimento de microrganismos resistentes à antimicrobianos busca-se métodos alternativos, que sejam eficientes e sustentáveis. O ozônio, um gás instável e oxidante, apresenta-se como uma possibilidade frente a esse problema pois pode atuar na eliminação de vírus, bactérias, fungos e parasitos. $\mathrm{O}$ objetivo deste trabalho foi avaliar a atividade antimicrobiana in vitro do gás ozônio em meios com grande quantidade de contaminação microbiana. Foram utilizadas duas concentrações do gás (2,5 e 10 ppm) nos tempos de contato de 30 minutos, 1, 2 e 4 horas em cepas bacterianas e fúngicas padronizadas e não padronizadas (Enterococcus faecalis- ATCC 19433, Listeria monocytogenes- ATCC 1911, Pseudomonas aeruginosa - ATCC 27853, Salmonella Typhimurium ATCC 14028, Staphylococcus aureus- ATCC 25923, Aspergillus niger - fungo filamentoso isolado do ambiente e a levedura Candida albicans- ATCC 10231) nas concentrações de 105 e 106 UFC/mL. O ozônio a 2,5 ppm apresentou ação antimicrobiana frente a todos os microrganismos na concentração 105 UFC/mL, exceto em E. faecalis, P. aeruginosa e S. Typhimurium na concentração $106 \mathrm{UFC} / \mathrm{mL}$. Na concentração de $10 \mathrm{ppm}$, todos os microrganismos tiveram redução em $105 \mathrm{UFC} / \mathrm{mL}$, e somente C. albicans foi eliminada nas duas concentrações de ozônio. O ozônio, frente aos microrganismos e concentrações utilizadas, apresentou atividade antimicrobiana, principalmente na concentração de 10 ppm, constituindo, assim, um método alternativo e eficiente na eliminação de patógenos.

Palavras-chave: Ozonização; Bactérias; Fungos; Desinfecção; Crescimento microbiano.

\section{Evaluation antimicrobial activity in vitro of ozone gas}

With the emergence of microorganisms resistant to antimicrobials, alternative methods are being sought, which are efficient and sustainable. Ozone, an unstable and oxidizing gas, presents itself as a possibility in the face of this problem as it acts in the elimination of viruses, bacteria, fungi and parasites. The objective of this work was to evaluate in vitro antimicrobial activity of ozone gas in environments with high microbial contamination. Ozone gas ( 2.5 and 10 ppm) were used in the contact times of 30 minutes, 1, 2 and 4 hours in standardized and non-standard bacterial and fungal strains (Enterococcus faecalis- ATCC 19433, Listeria monocytogenes- ATCC 1911, Pseudomonas aeruginosa - ATCC 27853, Salmonella Typhimurium ATCC 14028, Staphylococcus aureus- ATCC 25923, Aspergillus niger - filamentous fungus isolated from the environment and yeast Candida albicans- ATCC 10231) at 105 and 106 CFU/mL. Ozone at 2.5 ppm showed antimicrobial action against all microorganisms at a concentration of $105 \mathrm{CFU} / \mathrm{mL}$, except for E. faecalis, P. aeruginosa and S. Typhimurium at a concentration of $106 \mathrm{CFU} / \mathrm{mL}$. At a concentration of $10 \mathrm{ppm}$, all microorganisms were reduced by $105 \mathrm{CFU} / \mathrm{mL}$, and only C. albicans was eliminated in both ozone concentrations. Ozone, against the microorganisms and used, presents the antimicrobial activity, mainly in the concentration of $10 \mathrm{ppm}$, thus constituting an alternative and efficient method for the elimination of pathogens.

Keywords: Ozonation; Bacteria; Fungi; Disinfection; Microbial growth.

Topic: Microbiologia Agrícola e Ambiental

Reviewed anonymously in the process of blind peer.
Received: 08/06/2021

Approved: 24/06/2021
Thaís Aparecida Lamb (iD)

Universidade do Vale do Taquari, brasil

http://lattes.cnpq.br/9643771757289568

http://orcid.org/0000-0002-2499-5028

talamb@universo.univates.br

Amanda Luísa Stroher (iD

Universidade do Vale do Taquari, brasil

http://lattes.cnpq.br/3000433239780305

http://orcid.org/0000-0003-4279-8279

amanda.stroher@univates.br

Alberto Valdameri (D)

Universidade do Vale do Taquari, brasil

http://lattes.cnpq.br/7471412252760992

http://orcid.org/0000-0001-5374-0342

alberto@alvap.com.br

\author{
Vanderlei Biolchi (it) \\ Universidade do Vale do Taquari, brasil \\ http://lattes.cnpq.br/9483473607640009 \\ http://orcid.org/0000-0002-2206-5855 \\ vanderlei.biolchi@univates.br \\ Mônica Jachetti Maciel (iD \\ Universidade do Vale do Taquari, brasil \\ http://lattes.cnpq.br/2575088289818885 \\ http://orcid.org/0000-0002-6863-2181 \\ monicajm@univates.br
}

\section{Referencing this:}

LAMB, T. A.; STROHER, A. L.; VALDAMERI, A.; BIOLCHI, V.; MACIEL, M.

J.. Avaliação da atividade antimicrobiana in vitro do gás ozônio.

Revista Ibero Americana de Ciências Ambientais, v.12, n.6, p.152-

159, 2021. DOI: http://doi.org/10.6008/CBPC2179-

6858.2021.006.0013 


\section{INTRODUÇÃO}

Desde o surgimento do homem na Terra, diariamente, os seres vivos convivem com milhões de microrganismos, que podem ser encontrados em superfícies, alimentos, no ar e nos indivíduos. Muitos são inofensivos e podem inclusive ser benéficos para a saúde e para a sociedade, como aqueles usados na produção de alimentos e medicamentos. Porém, existem aqueles que causam doenças, chamados patogênicos, e podem acometer o sistema imunológico por meio da ingestão de alimentos e contato com superfícies, objetos e ar contaminados (TORTORA et al., 2012).

Com o surgimento das atividades relacionadas à saúde, a construção de ambientes hospitalares e aparecimento de práticas cirúrgicas e ambulatoriais, o ser humano deparou-se com o fator infecção. No começo, sem saber da existência dos microrganismos patogênicos, os procedimentos eram feitos sem cuidados com a higiene e limpeza do local e materiais utilizados. Com o passar do tempo e a evolução do conhecimento, a importância da atenção aos processos de limpeza e higiene foi aumentando, dando origem a métodos de higienização como desinfecção e esterilização, especialmente em ambientes hospitalares e estabelecimentos alimentícios (KALIL et al., 1994).

Segundo a Agência Nacional de Vigilância Sanitária (ANVISA, 2004), a taxa de infecções hospitalares no Brasil é de 15\%, enquanto na Europa e EUA é de 10\%. A infecção hospitalar ou nosocomial é uma das principais causas de morte entre os pacientes hospitalizados. De acordo com Khan et al. (2017), o número de pacientes infectados na UTI atinge a taxa 51\%. Nos países desenvolvidos o índice de infecções desse tipo é de $7 \%$, enquanto nos países em desenvolvimento pode chegar a $10 \%$. As infecções nosocomiais aumentam o tempo de internação do paciente, elevando os gastos com saúde e taxas de mortalidade. Por isso, é necessária a definição de processos e protocolos de limpeza e higienização que envolvam a rotina e mantenham baixa a concentração de agentes patogênicos, reduzindo as chances de infeções (DOMINGUES et al., 2011).

Nesse contexto, a desinfecção e esterilização constituem processos importantes para a sanitização de ambientes. A desinfeç̧ão é um processo físico e químico capaz de destruir ou inativar a maioria dos microrganismos presentes em objetos inanimados e superfícies, exceto esporos bacterianos (ANVISA, 2010). A esterilização destrói todas as formas de vida presentes nas superfícies, desde formas vegetativas e esporuladas, até vírus e fungos. Esses processos podem ser realizados por meio de diversas substâncias que atuam na estrutura e metabolismos dos microrganismos, eliminando-os (FRENCH et al., 2004).

O ozônio é um agente que pode ser utilizado na desinfecção. Apresenta como característica ser um gás instável, oxidante extremamente forte e pode reagir com inúmeros compostos orgânicos em decorrência de seu elevado potencial de redução (MENDES, 2010). Diferentemente de outros desinfetantes, o ozônio atua diretamente na parede celular de bactérias e fungos, levando-os à morte em milésimos de segundo em função da oxidação das proteínas dos microrganismos, com consequente inativação enzimática (SILVA et al., 2011). Esse gás também promove a inativação dos microrganismos ao se unir aos componentes citoplasmáticos e oxidar os aminoácidos e os ácidos nucleicos desses indivíduos (MARTINS et al., 2015). 
Como antimicrobiano, o ozônio foi utilizado pela primeira vez em 1893, para o tratamento de água na cidade de Oudtshoorn, na Holanda (LANGLAIS et al., 1991), sendo considerado um produto seguro para o tratamento hídrico pelo Food and Drug Administration (FDA) em 1982 (RUSSEL et al., 1999). No Brasil, começou a ser utilizado em 1983 (LAPOLLI et al., 2005). Estudos demonstram que esse agente pode ser uma alternativa no combate a microrganismos multirresistentes, e que o efeito bactericida é proporcional ao tempo de ação do gás (TORMIN et al., 2016). Entretanto, ainda não são completamente conhecidos os efeitos tóxicos do ozônio aos humanos e outros animais. A falta de protocolos, de evidências científicas para algumas aplicações e de legislações e regulamentos ainda impossibilitam e bloqueiam o uso do ozônio em muitos espaços (MARTINEZ-SÁNCHEZ, 2014).

A Organização Mundial da Saúde (OMS) estabeleceu, em 2005, que a exposição máxima ao ozônio não deve ultrapassar 0,1ppm, pois neste nível os efeitos à saúde podem não ser sentidos pela população. Ainda, para o padrão primário de 8 horas de exposição ao ozônio, a concentração do gás deve ser de 0,075 ppm (SANTANA et al., 2012). Nos Estados Unidos, a Agência Nacional da Qualidade do Ar Ambiental estabeleceu como valor de referência para uma exposição de 8 horas ao ozônio 0,070 ppm, enquanto na Austrália o limite de exposição ao ozônio é 0,080 ppm para quatro horas de exposição (SALONEN et al., 2018). No Brasil, o Ministério do Trabalho, por meio da Norma Regulamentadora $\mathrm{n}^{\circ} 15$, dispõe sobre os limites de exposição dos trabalhadores ao ozônio, estabelecendo que, para uma jornada de até 48 horas semanais, o limite de exposição seja de 0,080 ppm ou 0,16 mg/m³ (BRASIL, 1978).

Com a atual pandemia causada pelo vírus Sars-Cov-2, surgiram diversos equipamentos a base de ozônio que preconizam a eliminação de cepas do coronavírus com uso do ozônio solubilizado em água. Segundo a ANVISA, por meio da nota técnica № 108/2020, não existem comprovações científicas de que o ozônio possa ser utilizado de forma segura para desinfecção de ambientes e pessoas possivelmente contaminados pelo Sars-Cov-2. Para uso como tratamento antimicrobiano na indústria alimentícia, o órgão regulador não exige registro de autorização de uso. Os equipamentos geradores de ozônio são liberados apenas para uso na odontologia (ANVISA, 2020).

Para ensaio de comprovação da ação antimicrobiana, a ANVISA sugere o uso dos seguintes microrganismos: Staphylococcus aureus e Salmonella Choleraesuis; uso de Trichophyton mentagrophytes e Candida albicans para comprovação da atividade fungicida; e, para validação de atividade virucida, recomenda-se teste específico contra o vírus alvo (BRASIL, 2020). Frente ao exposto, este trabalho teve como objetivo avaliar a atividade antimicrobiana in vitro do gás ozônio.

\section{MATERIAIS E MÉTODOS}

Esta foi uma pesquisa quali-quantitativa que utilizou o procedimento técnico experimental de forma transversal. O experimento foi realizado na Universidade do Vale do Taquari- Univates (Lajeado, Rio Grande do Sul), em ambiente fechado (com dimensões de 1,10 $\mathrm{m} \times 2,50 \mathrm{~m} \times 2,10 \mathrm{~m}$ ), contendo placas de Petri contaminadas, separadamente, com os seguintes microrganismos: Enterococcus faecalis (ATCC 19433), Listeria monocytogenes (ATCC 1911), Pseudomonas aeruginosa (ATCC 27853), Salmonella Typhimurium 
(ATCC 14028), Staphylococcus aureus (ATCC 25923), Aspergillus niger (isolado do ambiente, cedido pelo Projeto de Pesquisa "Microbiologia em Sistemas Ambientais Sustentáveis", da Universidade do Vale do Taquari - Univates) e Candida albicans (ATCC 10231), nas concentrações de $10^{5}$ e $10^{6} \mathrm{UFC} / \mathrm{mL}$. As bactérias e os fungos foram ativados em placas de Petri contendo os meios de cultura Plate Count Agar (PCA- Merck) e ágar Sabouraud Dextrose (Merck) a $37{ }^{\circ} \mathrm{C}(24 \mathrm{~h})$ e a $25^{\circ} \mathrm{C}(72 \mathrm{~h})$, respectivamente. A partir da ativação, as bactérias e a levedura foram quantificadas fazendo-se o uso da escala de Mc Farland 0,5 (108 UFC/mL). Após, foram realizadas duas diluições decimais $\left(10^{7}\right.$ e $\left.10^{6} \mathrm{UFC} / \mathrm{mL}\right)$ e sucessivos plaqueamentos $(0,1 \mathrm{~mL})$, chegandose nas concentrações de $10^{6}$ e $10^{5} \mathrm{UFC} / \mathrm{mL}$. Para a quantificação de Aspergillus niger utilizou-se a Câmara de Neubauer para visualização e contagem dos esporos. Em seguida, foram realizadas diluições seriadas até que fossem atingidas as concentrações de $10^{6}$ e $10^{5} \mathrm{UFC} / \mathrm{mL}$. As placas de Petri com os microrganismos quantificados foram expostas ao ozônio nas concentrações de 2,5 e 10 ppm pelos tempos de contato de 30 minutos, 1 , 2 e 4 horas.

O gás ozônio foi gerado por descarga corona em equipamento modelo AV200 AR (Alvap ${ }^{\circledR}$ ), o qual tem capacidade de produção de $3 \mathrm{~g} / \mathrm{h}$, sendo utilizado o sensor (EcoSensor ${ }^{\circledR}$ ). A altura de exposição das placas foi de 1,5 m. Após o fim de cada período, as placas foram imediatamente incubadas em estufa durante 36 ㄷ por 48 horas (bactérias) e 25 ㄷ p por 72 horas (fungos).

Os testes foram realizados em triplicatas a fim de confirmar a efetividade do ozônio. Após os períodos de incubação, foi analisada a capacidade de inibição do crescimento microbiano pelo ozônio, por meio da observação e quantificação das UFC presentes nas placas. Foram tabuladas as quantificações das amostras e os resultados foram expressos em UFC/mL para as duas concentrações utilizadas. Para análise estatística foi realizado o teste ANOVA utilizando o programa SPSS (Statistical Package for the Social Sciences) versão 20.0. Foram considerados como significativos valores de $p \leq 0,05$.

\section{RESULTADOS E DISCUSSÃO}

Os resultados das contagens microbianas $\left(10^{5}\right.$ e $10^{6} \mathrm{UFC} / \mathrm{mL}$ ) em diferentes tempos de contato (30 min., 1 h, 2 h e 4 h) ao gás ozônio (2,5 e 10 ppm) estão na Tabela 1.

Tabela 1: Média dos resultados das exposições das placas de Petri (UFC/ $\mathrm{mL} \pm$ desvio-padrão) contendo $E$. faecalis, $L$. monocytogenes, P. aeruginosa, S. Typhimurium, S. aureus, A. niger, C. albicans, nas concentrações de $10^{5} \mathrm{e} 10^{6} \mathrm{UFC} / \mathrm{mL}$, frente ao ozônio (concentrações de 2,5 e 10 ppm) durante 0 min, 30 min, 1, 2 e 4h.

\begin{tabular}{|c|c|c|c|c|c|}
\hline \multirow[t]{2}{*}{ Microrganismos/ 2,5 ppm } & \multicolumn{5}{|c|}{ Tempo de exposição ao ozônio } \\
\hline & $0 \mathrm{~min}$ & $30 \mathrm{~min}$ & $1 \mathrm{~h}$ & $2 \mathrm{~h}$ & $4 \mathrm{~h}$ \\
\hline E. fecalis $10^{5}$ & $1 \times 10^{5}$ & $4,83 \times 10^{5} \pm 259^{*}$ & $5,08 \times 10^{5} \pm 226^{*}$ & $2,38 \times 10^{5} \pm 104^{*}$ & $3,17 \times 10^{5} 82^{*}$ \\
\hline E. fecalis $10^{6}$ & $1 \times 10^{6}$ & $1 \times 10^{6}$ & $1 \times 10^{6}$ & $1 \times 10^{6}$ & $1 \times 10^{6}$ \\
\hline L. monocytogenes $10^{5}$ & $1 \times 10^{5}$ & $2,07 \times 10^{5} \pm 26^{*}$ & $8,5 \times 10^{4} \pm 54^{*}$ & $1,56 \times 10^{5} \pm 56^{*}$ & $8,9 \times 10^{4} \pm 41^{*}$ \\
\hline L. monocytogenes $10^{6}$ & $1 \times 10^{6}$ & $3,3 \times 10^{4} \pm 113^{*}$ & $2,99 \times 10^{4} \pm 111^{*}$ & $2,34 \times 10^{4} \pm 108^{*}$ & $1,93 \times 10^{4} \pm 59^{*}$ \\
\hline$P$. aeruginosa $10^{5}$ & $1 \times 10^{5}$ & $1 \times 10^{5}$ & $7,68 \times 10^{5} \pm 38^{*}$ & $4,25 \times 10^{5} \pm 115^{*}$ & $4,13 \times 10^{5} \pm 272^{*}$ \\
\hline P. aeruginosa $10^{6}$ & $1 \times 10^{6}$ & $1 \times 10^{6 *}$ & $1 \times 10^{6}$ & $1 \times 10^{6}$ & $1 \times 10^{6}$ \\
\hline S. Typhimurium $10^{5}$ & $1 \times 10^{5}$ & $1 \times 10^{5}$ & $1 \times 10^{5}$ & $7,69 \times 10^{5} \pm 236^{*}$ & $4,45 \times 10^{5} \pm 296^{*}$ \\
\hline S. Typhimurium $10^{6}$ & $1 \times 10^{6}$ & $1 \times 10^{6}$ & $1 \times 10^{6}$ & $1 \times 10^{6}$ & $1 \times 10^{6}$ \\
\hline S. aureus $10^{5}$ & $1 \times 10^{5}$ & $1 \times 10^{5}$ & $1 \times 10^{5}$ & $8,9 \times 10^{5} \pm 207^{*}$ & $2,09 \times 10^{5} \pm 262^{*}$ \\
\hline S. aureus $10^{6}$ & $1 \times 10^{6}$ & $1 \times 10^{6}$ & $1 \times 10^{6}$ & $1 \times 10^{6}$ & $8,6 \times 10^{2} \pm 17^{*}$ \\
\hline A. niger $10^{5}$ & $1 \times 10^{5}$ & $1 \times 10^{5}$ & $1 \times 10^{5}$ & $7,7 \times 10^{4} \pm 20^{*}$ & $5,4 \times 10^{4} \pm 28^{*}$ \\
\hline A. niger $10^{6}$ & $1 \times 10^{6}$ & $1 \times 10^{6}$ & $1 \times 10^{6}$ & $1 \times 10^{6}$ & $9 \times 10^{3} \pm 13^{*}$ \\
\hline
\end{tabular}




\begin{tabular}{|c|c|c|c|c|c|}
\hline C. albicans $10^{5}$ & $1 \times 10^{5}$ & $1,68 \times 10^{5} \pm 83^{*}$ & $4,1 \times 10^{4} \pm 17^{*}$ & $4,5 \times 10^{4} \pm 4,5^{*}$ & $0 *$ \\
\hline C. albicans $10^{6}$ & $1 \times 10^{6}$ & $3,96 \times 10^{4} \pm 101^{*}$ & $2,7 \times 10^{3} \pm 20^{*}$ & $1,5 \times 10^{3} \pm 15^{*}$ & 0* \\
\hline Microrganismos/ 10 ppm & $0 \mathrm{~min}$ & $30 \mathrm{~min}$ & $1 \mathrm{~h}$ & $2 \mathrm{~h}$ & $4 \mathrm{~h}$ \\
\hline E. faecalis $10^{5}$ & $1 \times 10^{5}$ & $1 \times 10^{5}$ & $1 \times 10^{5}$ & $3,09 \times 10^{4} \pm 53^{*}$ & $1,5 \times 10^{4} \pm 26^{*}$ \\
\hline E. faecalis $10^{6}$ & $1 \times 10^{6}$ & $1 \times 10^{6}$ & $1 \times 10^{6}$ & $1 \times 10^{6}$ & $6,67 \times 10^{5} \pm 57$ \\
\hline L. monocytogenes $10^{5}$ & $1 \times 10^{5}$ & $2,65 \times 10^{4} \pm 77^{*}$ & $2,27 \times 10^{4} \pm 9 *$ & $1,61 \times 10^{5} \pm 99 *$ & $5 \times 10^{3} \pm 48^{*}$ \\
\hline L. monocytogenes $10^{6}$ & $1 \times 10^{6}$ & $2,4 \times 10^{4} \pm 108^{*}$ & $5,28 \times 10^{4} \pm 42^{*}$ & $3,29 \times 10^{4} \pm 83^{*}$ & $1,36 \times 10^{4} \pm 10^{*}$ \\
\hline P. aeruginosa $10^{5}$ & $1 \times 10^{5}$ & $4,85 \times 10^{4} \pm 298^{*}$ & $1,01 \times 10^{4} \pm 62^{*}$ & $1 \pm 1^{*}$ & $0 *$ \\
\hline P. aeruginosa $10^{6}$ & $1 \times 10^{6}$ & $1 \times 10^{6}$ & $2,59 \times 10^{4} \pm 104$ & $1,7 \times 10^{3} \pm 13$ & $1 \pm 1$ \\
\hline S.Typhimurium $10^{5}$ & $1 \times 10^{5}$ & $4,7 \times 10^{4} \pm 217^{*}$ & $3,03 \times 10^{4} \pm 98^{*}$ & $1,83 \times 10^{4} \pm 95^{*}$ & $9,1 \times 10^{3} \pm 27^{*}$ \\
\hline S. Typhimurium $10^{6}$ & $1 \times 10^{6}$ & $4,26 \times 10^{4} \pm 58^{*}$ & $2,05 \times 10^{4} \pm 8^{*}$ & $2,36 \times 10^{4} \pm 125^{*}$ & $2,3 \times 10^{4} \pm 156^{*}$ \\
\hline S. aureus $10^{5}$ & $1 \times 10^{5}$ & $1 \times 10^{5}$ & $6,68 \times 10^{4} \pm 57$ & $4,3 \times 10^{3} \pm 17^{*}$ & $0 *$ \\
\hline S. aureus $10^{6}$ & $1 \times 10^{6}$ & $1 \times 10^{6}$ & $1 \times 10^{6}$ & $2,91 \times 10^{4} \pm 47^{*}$ & $1 \pm 1 *$ \\
\hline A. niger $10^{5}$ & $1 \times 10^{5}$ & $1 \times 10^{5}$ & $2,8 \times 10^{3} \pm 8^{*}$ & $1,2 \times 10^{3} \pm 3^{*}$ & $1,5 \times 10^{3} \pm 9 *$ \\
\hline A. niger $10^{6}$ & $1 \times 10^{6}$ & $1 \times 10^{6}$ & $6,8 \times 10^{3} \pm 12^{*}$ & $3, \times 10^{3} \pm 17^{*}$ & $1,7 \times 10^{3} \pm 4^{*}$ \\
\hline C. albicans $10^{5}$ & $1 \times 10^{5}$ & $6,9 \times 10^{3} \pm 58^{*}$ & $3 \pm 1 *$ & $0^{*}$ & $0^{*}$ \\
\hline C. albicans $10^{6}$ & $1 \times 10^{6}$ & $2,15 \times 10^{4} \pm 157^{*}$ & $1,5 \times 10^{3} \pm 7^{*}$ & $4 \pm 4 *$ & $0 *$ \\
\hline
\end{tabular}

${ }^{*} \mathrm{P} \leq 0,05$ comparado ao tempo zero (0). Quando as contagens dos microrganismos nas placas eram incontáveis foram utilizadas as concentrações iniciais da cultura (ou $10^{6}$ ou $10^{5} \mathrm{UFC} / \mathrm{mL}$ ).

Analisando os resultados, percebe-se que algumas bactérias (Tabela 1) são mais suscetíveis ao ozônio na concentração de $2,5 \mathrm{ppm}$, como L. monocytogenes e $S$. aureus, que apresentaram o menor crescimento microbiano após $4 \mathrm{~h}$ de exposição, nas concentrações de $10^{6}$ e $10^{5} \mathrm{UFC} / \mathrm{mL}$, respectivamente. Foi possível observar que, nos tempos de $30 \mathrm{~min}, 1$, 2 e 4 h, houve redução na contagem da maioria dos microrganismos já na concentração de 2,5 ppm de ozônio, exceto para $P$. aeruginosa $10^{6}$ e $S$. Typhimurium $10^{6}$. Isso se repete na concentração de 10 ppm, na qual não houve crescimento em nenhuma concentração para C. albicans após $4 \mathrm{~h}$ de exposição. $\mathrm{O}$ mesmo aconteceu para as cepas de $S$. aureus $10^{5}$ e $P$. aeruginosa $10^{5}$ após $4 \mathrm{~h}$ expostas a 10 ppm de ozônio. Para esses microrganismos, na concentração $10^{6} \mathrm{UFC} / \mathrm{mL}$, houve crescimento de apenas $1 \mathrm{UFC} / \mathrm{mL}$ no tempo de $4 \mathrm{~h}$, mostrando grande redução se comparadas a concentração inicial (tempo zero).

Em consonância aos resultados deste trabalho, um estudo avaliou em mirtilos mantidos sob duas condições de temperatura ( 4 으 e 12 ํC) e expostos a duas concentrações de ozônio (4 ppm e 2,5 ppm) a sobrevivência de L. monocytogenes na concentração $10^{9} \mathrm{UFC} / \mathrm{mL}$. O estudo concluiu que o ozônio reduziu a contagem bacteriana em 3 e 2 log, respectivamente, quando comparado aos tratamentos a que as frutas foram expostas (CONCHA-MAYER et al., 2014). Em relação as bactérias S. aureus, E. faecalis e P. aeruginosa, foi possível observar redução de $3 \log$ somente em S. aureus exposta ao ozônio na concentração de 2,5 ppm durante $4 \mathrm{~h}$, na diluição $10^{6} \mathrm{UFC} / \mathrm{mL}$. Já na diluição $10^{5}$, também em 2,5 ppm de ozônio, foi observada redução de 3 log para os três microrganismos acima citados. Na concentração de ozônio a 10 ppm, a redução nas contagens microbianas foi mais pronunciada em 2 e $4 \mathrm{~h}$ nas duas diluições utilizadas.

Utilizando E. fecalis. resistente à vancomicina, P. aeruginosa e S. aureus, Tormin et al. (2016) avaliaram a eficácia do ozônio gasoso, chegando à conclusão de que após quatro minutos de exposição das suspensões de microrganismos ao ozônio na concentração de 0,01 ppm não foi possível observar crescimento significativo de colônias. No entanto, o ozônio foi aplicado em mais duas concentrações: 0,003 ppm e 0,004 ppm e, nestas, foi possível observar redução no crescimento, mas não de forma significativa.

Ainda, Fontes et al. (2012) realizaram estudo para avaliar o efeito de doses baixas de ozônio sobre bactérias patogênicas. Foram utilizadas as seguintes cepas bacterianas: Escherichia coli, S. aureus, E. fecalis, 
Klebsiella pneumoniae, Acinetobacter baumannii e P. aeruginosa. Os autores inicialmente fizeram um projeto piloto para verificar a concentração de ozônio e o tempo de exposição necessários para reduzir a carga microbiana das placas. A concentração inicial do inoculo nas placas foi de 0,1 ppm e o tempo de exposição foi de $1 \mathrm{~h}$. Os autores chegaram à concentração de 0,02 ppm e o tempo de exposição foi de 5 minutos que levou à inibição do crescimento das colônias bacterianas.

Em comparação a presente pesquisa, Nicolau (2016) realizou estudo para comparar diferentes desinfetantes no processo de descontaminação de carcaças de frango. Foram utilizadas duas concentrações de ozônio (0,3 e 1,2 ppm) e chegou-se à conclusão de que o ozônio não apresentou ação sobre Salmonella sp.na concentração de $10^{8} \mathrm{UFC} / \mathrm{mL}$. Além disso, a maior concentração do gás que foi utilizada não apresentou mais efetividade do que a menor. 0 estudo concluiu que o gás ozônio utilizado em combinação com o ácido láctico foi mais efetivo na eliminação do patógeno.

Werlang (2015) avaliou a eficácia da aplicação do ozônio gasoso em carcaças suínas a fim de controlar bactérias causadoras de doenças transmitidas por alimentos. Foi analisada a contagem de microrganismos aeróbios mesófilos totais e detectada a presença de Salmonella sp., Listeria sp. e E. coli. As concentrações de ozônio utilizadas foram 5 e 7 ppm e a concentração bacteriana foi de $10^{4} \mathrm{UFC} / \mathrm{mL}$. A pesquisa concluiu que a aplicação de ozônio em câmara fria, com o intuito de afetar o crescimento bacteriano, não foi capaz de reduzir a contagem das bactérias testadas.

Neste estudo, ao avaliar-se a redução nas contagens do fungo e da levedura, foi possível observar que, sobre estes dois microrganismos, o ozônio apresentou maior efetividade, tendo em vista que, nas duas diluições utilizadas e em todos os tempos de exposição, foi possível observar reduções de crescimento nas ordens de 2 e 3 log. É importante salientar que, em C. albicans, após 4 h de exposição ao gás, não houve crescimento de colônias.

Ferro et al. (2019) avaliaram diferentes tempos e concentrações de ozônio para inativar C. albicans in vitro, na concentração de $1,50 \times 10^{3} \mathrm{UFC} / \mathrm{mL}$. Os autores tiveram como resultado, $100 \%$ de inativação das colônias, com a exposição das placas a 65 ppm de ozônio. Na presente pesquisa, C. albicans foi 100\% inativada às $4 \mathrm{~h}$ de contato, nas concentrações microbianas de $10^{6} \mathrm{UFC} / \mathrm{mL}$ (2,5 e $10 \mathrm{ppm}$ de ozônio) e $10^{5}$ $\mathrm{UFC} / \mathrm{mL}(2,5 \mathrm{ppm})$. Já na concentração de $10 \mathrm{ppm}$ com quantidade menor de microrganismos $\left(10^{5} \mathrm{UFC} / \mathrm{mL}\right)$ às 2 horas de contato as leveduras haviam sido 100\% inativadas.

Gonzaga et al. (2018), avaliaram a atividade bactericida do ozônio em doses que variaram de 280 a $1400 \mathrm{mg} / \mathrm{L}$ em resíduos sólidos coletados de um hospital particular. Os resultados encontrados sugeriram a eliminação de 99,9\% dos microrganismos já com 10 minutos de exposição na concentração de 280 mg/L. Após análise microbiológica, os autores identificaram os seguintes microrganismos nos resíduos coletados: E. coli, P. aeruginosa, Proteus spp., S. aureus, Staphylococcus spp., C. albicans e Rhizopus spp., em concordância com as espécies testadas neste trabalho. Os autores do estudo citaram ainda as vantagens econômicas da ozonização em relação à esterilização por conversão e autoclave, demonstrando seus benefícios para o tratamento de resíduos hospitalares.

Nos trabalhos pesquisados para a elaboração deste estudo (PEREIRA et al., 2011; PEZZI, 2010), as 
concentrações de gás ozônio utilizadas variaram bastante $(0,25$ ppm a 300 ppm), sendo que, em alguns casos, a sua efetividade foi bem evidente. Nesta pesquisa, primeiramente a concentração de ozônio utilizada foi de 10 ppm, e, para verificar se haveria redução também em concentração menor, foi utilizada a concentração de 2,5 ppm. As concentrações utilizadas se mostraram eficazes na redução da contagem microbiana na maioria das cepas analisadas.

Em relação à concentração de microrganismos utilizada neste estudo, quando comparada às concentrações utilizadas em outros trabalhos, é possível verificar que alguns dos autores citados utilizaram a mesma concentração inicial (100), enquanto que outros utilizaram concentrações menores (NICOLAU, 2014). Neste estudo, foi verificada a concentração do gás ozônio em meios contendo alta concentração de microrganismos, o que não reflete a realidade de contaminação em ambientes como por exemplo, estabelecimentos de saúde. Apesar da concentração de ozônio de 10 ppm ser mais efetivo, a concentração de 2,5 ppm poderia ser aceitável para a aplicação prática em estabelecimentos de saúde. Além disso, em concentrações mais baixas, aumentaria o tempo de vida-útil do aparelho, melhorando o custo-benefício deste, a fim de competir com solução químicas desinfetantes.

\section{CONCLUSÕES}

O ozônio nas concentrações utilizadas foi efetivo na diminuição da maioria das contagens microbianas. Quanto maior o tempo de aplicação do gás sobre alguns dos microrganismos, maior foi a efetividade deste, sendo mais eficiente na dose de 10 ppm e $4 \mathrm{~h}$ de exposição.

Pode-se constatar que, frente as condições deste trabalho, o ozônio é eficaz como agente microbiano, porém ainda faltam estudos para padronização das doses utilizadas, concentrações de microrganismos e efeitos da exposição sobre a saúde.

\section{REFERÊNCIAS}

ANVISA. Agência Nacional de Vigilância Sanitária. Manual de Microbiologia Clínica para o Controle de Infecção em Serviços de Saúde. Brasília: ANVISA, 2004.

ANVISA. Agência Nacional de Vigilância Sanitária. Nota técnica no 108, de 28 de outubro de 2020. Brasília: ANVISA, 2020.

ANVISA. Agência Nacional de Vigilância Sanitária. Resolução n 59, de 17 de dezembro de 2010. Brasília: ANVISA, 2010.

BRASIL. Ministério do Trabalho. Norma Regulatória $\mathrm{n}^{\circ}$ 15, de 06 de julho de 1978. Brasília: MT, 1978.

CONCHA-MEYER, A.; EIFERT, J.; WILLIAMS, R.; MARCHY, J.; WELBAUM, G.. Survival of Listeria monocytogenes on fresh blueberries (Vaccinium corymbosum) stored under controlled atmosphere and ozone. Journal of Food Protection, v.77, n.5, p.832-836, 2014. DOI: http://doi.org/10.4315/0362-028X.JFP-13-441
FERRO, A. C.; FERREIRA, A. P.; UTIAMA, A.; ARAÚJO, J.; NEVES, M.; BEGA, A.. A atividade inibitória do gás de ozônio em meio sólido e meio líquido sobre a Candida albicans in vitro. Revista Ibero-Americana de Podologia, v.1, n.1, p.3035, 2019. DOI: https://doi.org/10.36271/iajp.v1i1

FONTES, B.; HEIMBECKER, A. M. C.; BRITO, G. S.; COSTA, S. F.; VAN DER HEIJDEN, I. M.; LEVIN, A. S.; RASSLAN, S.. Effect of low-dose gaseous ozone on pathogenic bacteria. BMC Infectious Diseases, v.12, n.1, p.358, 2012.

FRENCH, G. L.; OTTER, J. A.; SHANNON, K. P.; ADAMS, N. M. T.; WATLING, D.; PARKS, M. J.. Tackling contamination of the hospital environment by methicillin-resistant Staphylococcus aureus (MRSA): a comparison between conventional terminal cleaning and hydrogen peroxide vapour decontamination. Journal of Hospital Infection, v.57, n.1, p.31-37, 2004

GONZAGA, T. N.; KOZUSNY-ANDREANI, D. I.. Utilização de gás ozônio na desinfecção de resíduos de serviços de saúde. Revista Interdisciplinar de Estudos em Saúde, v.7, n.2, p.125-139, 2018. DOI: http://doi.org/10.1016/i.jhin.2004.03.006 
KALIL, E. M.; COSTA, A. J. F.. Desinfecção e esterilização. Acta Ortopédica Brasileira, v.2, n.4, p.1-4, 1994.

KHAN, H. A.; BAIG, F. K.; MEHBOOB, R.. Nosocomial infections: Epidemiology, prevention, control and surveillance. Asian Pacific Journal of Tropical Biomedicine, v.7, n.5, p.478-482, 2017. DOI:

https://doi.org/10.1016/j.apjtb.2017.01.019

LANGLAIS, B.; RECKHOW, D. A.; BRINK, D. R.. Ozone in water treatment: application and engineering. Chelsea: AWWARF and Lewis Publishers, 1991.

LAPOLLI, F. R.; HASSEMER, M. E. N.; CARAGO, J. G.; DAÁSIO, D. L.; LOBO-RECIO, M. A.. Desinfecção de efluentes sanitários através de dióxido de cloro. Revista Engenharia Sanitária e Ambiental, v.10, n.3, p.200-208, 2015. DOI: https://doi.org/10.1590/S1413-41522005000300004

MARTINEZ-SÁNCHEZ, G.. The challenges of ozone therapy and access to sources of information. Revista Española de Ozonoterapia, v.4, n.1, p.87-89, 2014.

MARTINS, C. C.; KOZUSNY-ANDREANI, D. I.; MENDES, E. C. B. Ozônio no controle de micro-organismos em resíduos de serviços de saúde. Revista Baiana de Enfermagem, v.29, n.4, p.318-327, 2015.

MENDES, R. L.. Controle de compostos orgânicos precursores e subprodutos da desinfecção em mananciais eutrofizados mediante combinação de interozonização e sistemas pós-filtros adsorvedores. Tese (Doutorado) Universidade de São Paulo, São Paulo, 2010. DOI: http://dx.doi.org/10.18471/rbe.v29i4.13678

NICOLAU, J. P.. Controle de Salmonella sp.em carcaças de frango pelo uso de descontaminantes químicos durante o processo de abate e as consequências na qualidade da carne. Tese (Doutorado em Ciência Animal) - Universidade Estadual Paulista, São Paulo, 2016.

NICOLAU, P. B.. Métodos em microbiologia ambiental. 2014.

PEREIRA, A. P. M.; WERLE, C. H.; VINTURIM, T. M.;
HOFMANN, F. L.. Identification and evaluation of antimicrobial resistance of yeast in minimally processed vegetables. Revista do Instituto Adolfo Lutz, v.70, n.2, p.139-143, 2011.

PEZZI, E.. O uso do ozônio como sanitizante em pós-colheita de produtos agrícolas. Monografia (Especialização em Tecnologias Inovadoras no Manejo Integrado de Pragas e Doenças de Plantas) - Universidade Federal do Rio Grande do Sul, Porto Alegre, 2010.

RUSSEL, A. D.; HUGO, W. B.; AVLIFFE, G. A. J.. Principles and practice of disinfection, preservation and sterilization. 3 ed. Oxford: Blackwell Science, 1999.

SANTANA, E.; CUNHA, K. B.; FERREIRA, A. L.; ZAMBONI, A. Padrões de Qualidade do Ar: Experiência Comparada Brasil, EUA e União Europeia. São Paulo: Instituto de Energia e Meio Ambiente, 2012.

SALONEN, H.; SALTHAMMER, T.; MORAWSKA, L.. Human exposure to ozone in school and office indoor environments. Environment International, v.119, p.503-514, 2018. DOI: http://doi.org/10.1016/j.envint.2018.07.012

SILVA, S. B.; LUVIELMO, M. M.; GEYER, M. C..

Potencialidades do uso do ozônio no processamento de alimentos. Semina: Ciências Agrárias, v.32, n.2, p.659-682, 2011. DOI: http://doi.org/10.2312/ActaFish.2014.2.1.15-28

TORMIN, S. C.; NAVARRINI, A.; ALMEIDA, J. O.; TRAVASSOS, L. R.; NEGRI M. V. G.; SILVA, R. A.. Análise do efeito bactericida do ozônio sobre bactérias multirresistentes. Arquivos Médicos dos Hospitais e da Faculdade de Ciências Médicas da Santa Casa de São Paulo, v.61, n.3, p.138-141, 2016.

TORTORA, G. J.; FUNKE, B. R.; CASE, C. L.. Microbiologia. 10 ed. Porto Alegre: Artmed, 2012.

WERLANG, G. O.. Eficácia da aplicação de ozônio gasoso em carcaças suínas na etapa de resfriamento para o controle de bactérias indicadoras e causadoras de doenças transmitidas por alimentos. Dissertação (Mestrado em Medicina Veterinária) - Universidade Federal do Rio Grande do Sul, Porto Alegre, 2015.

A CBPC - Companhia Brasileira de Produção Científica (CNPJ: 11.221.422/0001-03) detém os direitos materiais desta publicação. Os direitos referem-se à publicação do trabalho em qualquer parte do mundo, incluindo os direitos às renovações, expansões e disseminações da contribuicão, bem como outros direitos subsidiários. Todos os trabalhos publicados eletronicamente poderão posteriormente ser publicados em coletâneas impressas sob coordenação da Sustenere Publishing, da Companhia Brasileira de Produção Científica e seus parceiros autorizados. Os (as) autores (as) preservam os direitos autorais, mas não têm permissão para a publicação da contribuição em outro meio, impresso ou digital, em português ou em tradução. 